\title{
Engaged Scholarship in Action: The Journey of the School Board - University Research Exchange (SURE) Network
}

\author{
Dragana Martinovic, Snežana Ratković, Terry Spencer, Arlene Grierson, \\ Maria Cantalini-Williams, Sally Landon
}

\begin{abstract}
In this paper we use a chronological case-study narrative format to detail the creation and progression of a School Board-University Research Exchange (SURE) network in Ontario, Canada. This network is led by a group of university- and school board-based professionals, who are committed to deepening connections between educational research, practice, and policy. Our narrative presents the SURE network's evolution using the metaphors of being "in the woods," looking for "our compass," and finding "new pathways" of engaged scholarship. We present the challenges and successes we experienced while crossing the borders of our individual and institutional cultural settings, emphasising the importance of continuing discussions and collaborations within and amongst our communities.
\end{abstract}

KEYWORDS school board-university partnership; community engagement; education; sustainability; research collaboration

Historically, academics and practitioners have been viewed as inhabiting in two distinct worlds (Bartunek \& Rynes, 2014; Garman, 2011; Shapiro, Kirkman, \& Courtney, 2007). While some scholars discuss new possibilities for bridging the gap between academics and practitioners (Vermeulen, 2005), others claim that the gap is increasing (Tsui, 2013). Uncovering tensions associated with the academic-practitioner gap can inform theory and "stimulate new types of scholarly inquiries" (Bartunek \& Rynes, 2014, p. 2), especially those inquiries related to scholar-practitioner partnerships. Our literature review demonstrates that similar gaps exist in different sectors, including business management, nursing, and education.

In education, on one hand, school teachers might perceive university research as irrelevant for classroom practice and/or that university researchers often focus on their personal research interest, rather than on school board needs and priorities (Garman, 2011; Martinovic, Wiebe, Ratkovic, Willard-Holt, Spencer, \& Cantalini-Williams, 2012). On the other hand, university researchers might feel that there is little to gain from including practitioners' priorities and perspectives in their programs of research (Garman, 2011). In attempts to foster mutual understanding and collaboration, in the last two decades, there has been a strong focus on developing partnerships between universities and schools (Ancess, Barnett, \& Allen, 2007; Coburn \& Penuel, 2016; Lang, 2001; Ramsey, 2000; Ross, Rolheiser, \& Hogaboam-Gray, 1999; 
Yardley \& Lock, 2004).

In part, to foster collaboration and effective use of data amongst school board partners, as part of its Research and Evaluation Strategy (Campbell \& Fulford, 2009), the Ontario Ministry of Education (OME) established seven regional planning bodies, which they named Managing Information for Student Achievement Professional Network Centres (MISA PNCs). These Centres function as "professional learning communities and assist in building capacity in boards and schools to work with data in support of evidence-informed decision-making and undertake a broad range of local research in this area" (OME, 2011). The London region MISA PNC is comprised of 16 district school boards and contains, within its boundaries, five faculties of education. The Research Subcommittee of this PNC approached deans of these faculties to determine their interest in establishing a network for promoting collaborative research initiatives with school boards. The purpose of such a network was to develop longlasting partnerships, create a regional research agenda, facilitate school-based research projects, and design ways for improving dissemination and use of research findings across school boards and universities. The initial meeting of representatives from most school boards and the deans/associate deans from the five universities was held in August 2008 and resulted in establishing the Research Exchange Steering Team. This team recognized that research and knowledge creation occur in both university and school settings and that reciprocity is the key to mutual benefit (Lefever-Davis, Johnson, \& Pearman, 2007). In attempts to foster this reciprocity, the team created the School Board-University Research Exchange (SURE) Steering Committee of about 15 members from representative school boards and universities.

Initially, the mission of SURE was "to develop and sustain an active collaborative relationship among universities and school districts in the OME London Region in order to inspire a culture of inquiry, advance skills, and promote knowledge exchange related to education research" (SURE Mission Statement, 2009). Since then, SURE developed a viable governance structure and committed to knowledge mobilization related to education research (Martinovic, Ratkovic, Wiebe, Willard-Holt, Spencer, \& Cantalini-Williams, 2012). This commitment to knowledge mobilization (KMb) is in congruence with Boyer's (1996) scholarship of engagement and his statement that the academy must engage with the community. Boyer explains: "The academy must become a more vigorous partner in the search for answers to our most pressing social, civic, economic, and moral problems, and must affirm its historic commitment to what I call the scholarship of engagement" (p. 18).

In June 2015, the current SURE Steering Committee decided to examine the SURE journey in order to develop a school board-university engagement model and the six co-authors of this paper volunteered to undertake this research. The authors are employed by two school boards and four faculties of education. Our Research Ethics Boards provided clearance to engage in the research during which we analyzed documents and materials collected over a seven year history of SURE's existence. In this paper, we explore the challenges and successes SURE experienced in the process of developing and sustaining community-engaged collaborative work in Southwestern Ontario. As engaged education scholars and practitioners, we address the imbalance in power relations in our work, and examine the genesis and evolution of the SURE network. 
We illustrate the challenges and affordances of network-initiated innovation and address the following research questions: What was the rationale for establishing the SURE network? How has SURE transitioned and evolved into a community-engaged network? What has sustained the existence of the network? What have been innovative features of SURE? What has been the impact of SURE on education practice, research, and policy?

Prior to this research, we had not interrogated in depth our group dynamics and feel that our findings have deepened our understanding of school board-university partnerships and community engagements, and will be useful for others who are embarking on a similar path. We suggest a number of implications for school board-university research networks that build on "tensions, dialectics, and paradox" (Bartunek \& Rynes, 2014, p. 2) when enacting "a community-engaged collaborative work ... in cross-cultural settings" (Khanenko-Friesen, 2015, p. 8). Our paper concludes with a brief reflection about the tensions we experienced during our journey and an acknowledgment of the contribution these tensions might make to theoretical and practical applications of school board-university research collaboration, as well as to education research, policy, and praxis. Within this paper we scrutinize and celebrate our SURE partnership, our engaged scholarship, and our contribution to the broad field of education.

\section{Treasure Hunt}

This essay uses a chronological case-study narrative format (Flyvbjerg, 2006) to describe the SURE network genesis and evolution. Such a dense case study format is more useful for practitioners and more intriguing for academics than summaries of findings or generalizations of theory (Peattie, 2001). We work with the assumption that context-dependent knowledge and experience are crucial in gaining new insights and developing expertise. Moreover, we concur with Flyvbjerg (2006) who claims that context-dependent knowledge and expertise "lie at the center of the case study as a research and teaching method" (p. 5). Following Flyvbjerg, we keep our case study open and tell our story in its diversity, complexity, and authenticity. We hope that such an approach will enable readers from different backgrounds to draw diverse conclusions while interpreting our journey.

Our case study has utilized a mixed methods research approach, one of which is qualitative content analysis (Kondracki \& Wellman, 2002) of multiple data sources collected between August 2008 and June 2015. These sources include minutes of the SURE Steering Committee meetings, research proposals, conference presentations, reports, posters, research briefs, and participants' feedback related to SURE KMb and engaged scholarship events. Appropriate when existing theory or literature on a phenomenon is limited, this type of content analysis served as a "method for the subjective interpretation of the content of text data through the systematic classification process of coding and identifying themes or patterns" (Hsieh \& Shannon, 2005, p. 1278). We avoided using preconceived categories (Kondracki \& Wellman, 2002) to describe the phenomenon of our school board-university collaboration and, instead, identified the categories as they emerged from the data. The analysis of multiple data sources and collaborative writing of this essay triggered the research team members' memories and 
feelings, some of which were then recorded and included in our narrative.

A quantitative research approach utilized a Self-Assessment survey based on Woodland and Hutton's (2012) Collaboration Evaluation and Improvement Framework (CEIF), appropriate for group self-assessment and triangulation with analyses of SURE meeting agendas and minutes. In February 2012, the Steering Committee invited all 23 of its past and present members to complete this anonymous, online survey, and nine of them responded. One item on the survey asked about the respondent's primary affiliation (i.e., university or district school board), while 22 items were adapted from the Team Collaboration Assessment Rubric (TCAR from CEIF), which on levels 0-2 evaluated different aspects of collaboration, such as dialogue, decisionmaking, action, and evaluation (see Appendix). The additional 16 open-ended items asked for more evaluative comments and suggestions, which addressed the level and the complexity of collaboration. These questions provided useful insights and enabled us to situate the experiences of SURE along two models of collaboration. First, the survey data were assessed through the four Stages of Collaboration Development Model (Gajda, 2004; Bailey \& Koney, 2000; Tuckman \& Jensen, 1977). The model includes Assemble and Form, Storm and Order, Norm and Perform, and Transform and Adjourn stages. At the Assemble and Form stage, partners are finding the value of coming together and discussing an initial vision and mission of the joint venture. At the Storm and Order stage, partners are establishing their individual roles and norms, while determining strategies, objectives, and outcomes. At the Norm and Perform stage, they act upon their goals and create the continuous feedback loop. At the Transform and Adjourn stage, reassessment and possible modifications take place. Second, we used Bailey and Koney's (2000) 4-level Continuum of Integration Scale for strengthening strategic alliances, where a common goal can be achieved through cooperation (i.e., independent groups share information to support each other's work), coordination (i.e., independent groups start aligning their activities), collaboration (i.e., individual groups give up some degree of independence); and coadunation (i.e., at least one partner gives up its autonomy). Quantitative analyses using these models of inter-organizational collaboration, together with our qualitative content data analyses allowed for a deep and comprehensive self-evaluation and analyses of our work.

\section{Our Journey}

In 2008, school board researchers in the London Region MISA PNC identified two main barriers to evidence-based educational practices. One barrier was that university research did not necessarily focus on school board research priorities nor did it seamlessly translate to classroom use. Another problem identified was the seeming "burden" to school boards of requests to conduct research in schools along with the perception that boards provided a convenient pool of research subjects (Short, 2009). There was a desire by school boards to be more involved in shaping the research agenda of university researchers and to find a common ground for knowledge exchange. As a result, the school board research subcommittee of the London regional MISA PNC proposed a school board-university partnership to the Deans of Education in the London region. The main aims of this initiative were to deepen relationships amongst five faculties of education and 16 school boards in this geographic 
area, enrich understanding and communication between these two communities, and enhance opportunities for collaboration and the creation of relevant and coordinated programs of research (Short, 2009).

\section{First Steps}

The impetus for SURE (originally known as the Research Exchange) was the outcome of a MISA PNC action research grant that four school board researchers of the London Region applied and received funding for in 2008. Their study was driven by the following research question: "What is the feasibility of establishing a Research Exchange with school district and university partners in the London Region?" The university deans and associate deans participating in this study found this initiative feasible and unanimously volunteered to be part of the London Region Research Exchange Steering Committee. This steering committee became the first step of SURE's journey. According to the mutual agreement, participation in the SURE community was voluntary and funded by MISA PNC from the outset, so none of the participating organizations were expected to contribute funds to SURE. All 16 district school boards (DSBs) and five faculties of education in the London region were invited to send their representatives to the Steering Committee, who met in London (ON) on March 10, 2009. In hindsight, the university members and representatives from the larger school boards attended the meetings regularly, while for the small school boards it was a challenge to do so because of the lack of research personnel. The MISA PNC representative also attended the SURE meetings and reported on the SURE activities during the regional MISA PNC meetings. Initially, deans of faculties of education were invited to join SURE, but most appointed associate deans, research leadership chairs, faculty members, and/or research officers as their representatives on the Committee. The membership of the DSBs included individuals responsible for overseeing research in each board with some of the individuals changing over time, which may have complicated the relationship building processes and the Steering Committee's work. The meetings of the Steering Committee were at first "designed to inspire open-ended thinking" (SURE, Minutes, March 10, 2009). They were not agenda-driven, although the intent was to generate group dialogue around mission and vision statements, and long-and short-term goals.

As recorded in the minutes of one of the first steering committee meetings (MISA Feasibility Pilot - Planning Next Steps, March 10, 2009), we noted that collaboration was about developing deep relationships, not simply a functional exchange of information on a website. We also recognized that there was impetus for collaboration from funders, and this may be particularly important in these economic times. The moment was right, as the school boards were beginning to meet with local universities to talk about common interests. We were aware that new faculty and graduate students were looking for sites to conduct their research and perceived that it would be feasible that they build a program of research around school board priorities. We also engaged in dialogue about questions with respect to research ethics review processes. As a result, we proposed sharing the application forms and data sharing protocols to streamline the review process across our member institutions. Finally, university partners clearly 
stated that conducting research in boards was a privilege, not a right, for university researchers.

At the core of establishing the SURE network was the need for a common understanding and common language among our members, and the Steering Committee was assigned with the task of bridging our "worlds." As outlined in our meeting minutes, we present some of the ideas shared during our initial meetings: universities could create a form for school boards to complete if they are looking for a potential collaborator on a given research topic; the OME officials in the London Region should be invited to join the Steering Committee; and we should engage educators in research partnerships through face-to-face events and a web-based presence (e.g., wiki). While some of these considerations took years to materialize (e.g., having a repository of research ethics forms of our member organizations on the SURE website) and some never came about (e.g., having the London Region OME officials as members of the Steering Committee), many innovative ideas and activities emerged from these initial beginnings. These ideas included creating an online database to match researchers and practitioners; developing a governance structure that defines what we do, such as working subcommittees; and meeting regularly (Moving Forward: New SURE Executive and Constitution, June 2013). The committee also obtained grants from various organizations to fund research and disseminate information, in addition to receiving annual funding of \$10,000 from the London MISA PNC to cover meeting and travel expenses, web design, and research-to-practice events. These grants and the events/conferences that SURE organized are detailed next within the "in the woods" and "our compass" sections of our paper, which document our processes of exploration and discovery.

\section{In the Woods}

SURE began with ad hoc, informal meetings and transitioned to a structured entity with a governance model and roles (see http://www.surenetwork.ca/about-us/) as it negotiated and created its role in education research, practice, and policy. In 2008, understandings of our two worlds deepened in terms of differing goals, logics, time dimensions, communication practices, rigour and relevance, interests and incentives. One factor that assisted us in the development of common understandings is that some of our members had worked in both the school board and university contexts. For example, at least two university faculty members had previously worked as school board consultants.

In our work plan for the 2008/09 school year, it was suggested that we (a) establish an electronic web platform for communication and sharing throughout the region, (b) annually conduct four Steering Committee meetings, (c) employ a graduate student project coordinator, (d) organize an Education Research Speaker Series where faculty members and school board representatives would exchange visits to discuss applied education research, (e) organize local Board and Faculty Research Roundtables, (f) establish a London Region Spring Research Conference, and (g) monitor our collaboration, while (h) securing additional funding for our activities. Over the years, most of these tasks were accomplished and some were modified to capitalize on other opportunities that arose. Starting from brainstorming potential needs, we transitioned from conducting research into teachers' perceptions of their research acumen and 
needs, to organizing research-to-practice festivals and developing a research-to-practice video series focussed on topics related to teachers-as-researchers.

The tensions and successes we experienced while finding our way "out of the woods" are reflected in the following retrospective narrative written by a DSB representative after reviewing our data and reflecting upon our journey, while co-authoring this paper. Concerns related to our differing worlds and the workload imbalance among the committee members were expressed:

Since the inception of the SURE Steering Committee, we have grappled with our differing timelines and logistics. We have recognized that DSB research timelines often do not fit university research grant or project deadlines. Additionally, time investment in SURE projects has differed among the committee members. For example, although everybody on the committee was invited, involvement of DSB representatives in writing a research report and a research paper was limited. Moreover, some MISA leaders faded away from the committee or dropped out of some individual SURE projects. Why? Maybe they did not have time or an incentive to engage with the SURE or its activities,

This problem was noted in our meeting minutes, where "[a DSB representative] stated challenge for people to value participation in SURE" and "[a university representative] commented on the turnover of staff; that this makes acculturation difficult" (SURE Steering Committee meeting minutes, September 19, 2014). Transitioned roles and portfolios of our members particularly complicated our DSB members' involvement in SURE activities.

In terms of logistics, some DSB representatives feared that other committee members might assert ownership over data and publications/presentations that were not necessarily vetted by the entire SURE committee. Most specifically, external funding provided through grants acquired by faculty members at universities (e.g., SSHRC Public Outreach Grant), created a tension around the influence of the MISA PNC or universities on the Committee agenda, project activities, and outcomes. Over time, we also needed to negotiate data ownership. For example, while writing a research paper about educators' use of research in the London region (Authors, 2012), we asked ourselves: "Who owns it? Is the paper a publication of the members of the writing team or a SURE publication?" These questions came up frequently at our meetings. While we wanted to work as a collective, we continued to wonder...

How does it work? How do you make it happen? How can we work and publish as a collective and establish a group/shared identity, rather than work collectively as two distinct groups that participate in projects from their respective areas of interest, priorities, and pressures? Who benefits from publishing an academic paper? Are the university researchers the only beneficiaries of SURE activities?

A university representative on SURE reflected on these tensions in the following manner: "We are volunteering our time and expertise to support teachers and students, stepping outside our field to further school board priorities. However, we do recognize potential of such partnership that surpasses any individual's personal goals." 
On the other hand, to secure regular MISA PNC funding, we were encouraged (if not pressured) to produce tangible and multiple $\mathrm{KMb}$ outcomes. We feel that our work strategies and relationships evolved organically through continuing conversation, collaboration, and commitment, and in hindsight realise that it would have been helpful to discuss our trajectories and practices more frequently and in more detail, despite the pressure to produce "tangible" outcomes. Not recognising these tensions and collectively deciding whether or not it was mutually beneficial to work this way, might have left some committee members feeling guilty while others might have felt overworked. How do we reconcile this incongruence? Can we reconcile it if we talk about our differing pressures and priorities and the role SURE plays in our professional lives? Over time, we have noticed that when we operate as a collective with a single SURE identity, we present ourselves as equal members. This was evident during our conferences/events and our presentations at other conferences. The reality beneath the surface is, however, that we are just assuming this equal membership. We contribute in different ways. How can we quantify and acknowledge the various contributions? Analyzing our data and writing this paper provided us with the opportunity to re-think our differences as well as collective accomplishments; it helped us recognize our collective identity and not only celebrate our common goals and achievements, but also acknowledge our disagreements and silences.

In retrospect, some of our long-term DSB members believe that SURE was about ideas, about sharing information freely and collaborating with Deans in attempts to change the research culture in the faculties of education. In the view of these DSB members, Deans of Education were expected to encourage university researchers to develop programs of research that would be more relevant to the DSBs' needs and priorities. Did the mission of this group change from the inception? In a written narrative about their experiences in SURE, a DSB representative noted:

\begin{abstract}
We were not originally intending to be a working engine. Was it naive to think that we would be a think tank? Project reporting became our meeting agenda, rather than bouncing of ideas. Our initial purpose/mission was about aligning teachings of the education students and research priorities; making the faculties of education aware about the realities in the classroom. The faculties struggled with the boards' research review processes and barriers to conducting research. It is safe to assume that boards would be motivated to take down some barriers if the faculties' research is aligned with boards' priorities; the boards would be more inclined to facilitate the process. Past experiences of the boards are that researchers would get data and run away with them. The boards wanted to change it. They could learn and benefit from research conducted in their schools. Deans were expected to influence the change in the research culture of the faculties of education-to benefit the community/schools; to bring about what the boards envisioned-community-based research in the faculties of education.
\end{abstract}

Some of our university representatives reiteratively wondered: How critical is it to have 
deans and superintendents of education on the SURE Steering Committee? How would they shape (or transform) SURE network's mission, vision, and role within educational theory, practice, and policy?

Over time, we have evolved into a group of leaders-in-the-middle and our goals have changed. Our challenge became to figure out how we can accomplish what we set out to accomplish within our current group reality. That is a conversation we have not pursued persistently until engaging with this research. Maybe we can affect change incrementally by fostering university and school board partnerships and reaching out to our organizational leaders. Maybe our original vision needs to change. Maybe we need to focus on developing and modelling school board and university collaborative work, exploring where we can go with it, who we can reach, and what outcomes we can achieve-documenting the journey, struggles, and victories as a model for other community engaged partnerships. Ultimately, we needed to carve out time to have these reflective conversations, embrace the growing pains and tensions, and discuss what we are learning from it. This collective writing process has reconfirmed that relationships have remained a key factor for us.

\section{Our Compass}

As we embarked on our journey, we encountered multiple road blocks, but we were also able to leave a new trail in the field of education research and engaged scholarship. Over time, we used different opportunities to assess our collaboration and educational community engagement, and develop new directions. Some of these opportunities that we used for deepening our understanding of group dynamics and performance included a self-assessment survey of committee members, participants' feedback following SURE events, and development of our governance structure.

\section{Self-assessment Survey}

In the fall of 2011, we were invited to submit a presentation proposal for a 2012 Ontario Education Research Symposium (OERS). The symposium was focused on the theme of research impact. That prompted us to reflect on our journey, and assess the degree and nature of our collaboration. The results of the SURE self-assessment survey (40\% response rate, 6 university and 3 DSB respondents) revealed tensions, complexities, and paradoxes, some of which relate to ownership of data, authorship over the KMb products, engagement levels, and the SURE as an idea-generator vs. producer-of-research (see Appendix).

In each of the categories considered by the Team Collaboration Assessment Rubric (Woodland \& Hutton, 2012), we identified both our strengths and areas for improvement. For example, in the area of Action, we identified strengths related to coordination, work ethics, and collaboration. According to one survey participant, a strong work ethic was very important in motivating other members to complete assigned tasks: "Work ethic of some members is inspirational." When describing our collaboration processes (i.e., our professional and personal engagement with each other), another participant used the words: "Amazing! Inspiring! Promising!" 
At the same time, varied involvement and/or contribution of committee members was listed as a primary concern by seven out of nine respondents. One of them explained:

I think that distribution of action-taking is unbalanced, but I cannot say it is unfair; I don't know why some members are more active than others. Do we need to learn more about each other priorities and constrains, about new ways of supporting each other and breaking barriers to action and productivity? (Self-Assessment Survey participant)

While articulating this concern, the participants also made the further suggestions such as "Make use of collaborative tools (Skype, Google Docs, and Doodle) for action-planning."

Our participants reported the following strengths of our collaboration: (a) building upon and recognizing the skills and expertise of individual members; (b) informing the partners in a realistic manner of our unique needs; (c) working well together; (d) making impact within member boards, faculties of education, and across the province; (e) developing relationships and building trust; and ( $f$ ) bringing together so many different organizations in a unique partnership. We identified funding from the MISA PNC, dual SURE-MISA PNC roles, team work, supportive administration, keen interest in applied education research, and familiarity with people already on SURE as enabling factors for our successful collaboration. At the same time, we encountered multiple challenges associated with issues of power and unequal contribution; different needs, interests, and incentives among the partners; geographical distance of our member institutions; conflicting schedules; heavy personal workloads; and lack of guiding principles.

Based on this Self-Assessment survey, SURE was at the Norm and Perform stage of the Stages of Collaboration Development Scale (Gajda, 2004; Bailey \& Koney, 2000; Tuckman \& Jensen, 1977) and at the Collaboration stage on the Continuum of Integration Scale for Strengthening Strategic Alliances (Gajda, 2004; Bailey \& Koney, 2000). After considering these different models of collaboration and integration, we concluded that our development was emergent and that the journey metaphor best reflected our key structures and processes. It became evident to us that we had shifted our focus from our differences to our commonalities, and created a new scholarship of engagement model (see Figure 1). Our team self-evaluation revealed some weaknesses, such as lack of focus on the SURE practice and performance in a dialogue. This resulted in the use of a standardized format for creating and documenting meeting agendas and minutes. In terms of decision-making, we decided that being flexible and open for (and supportive of) different levels of contribution should be our stance. 


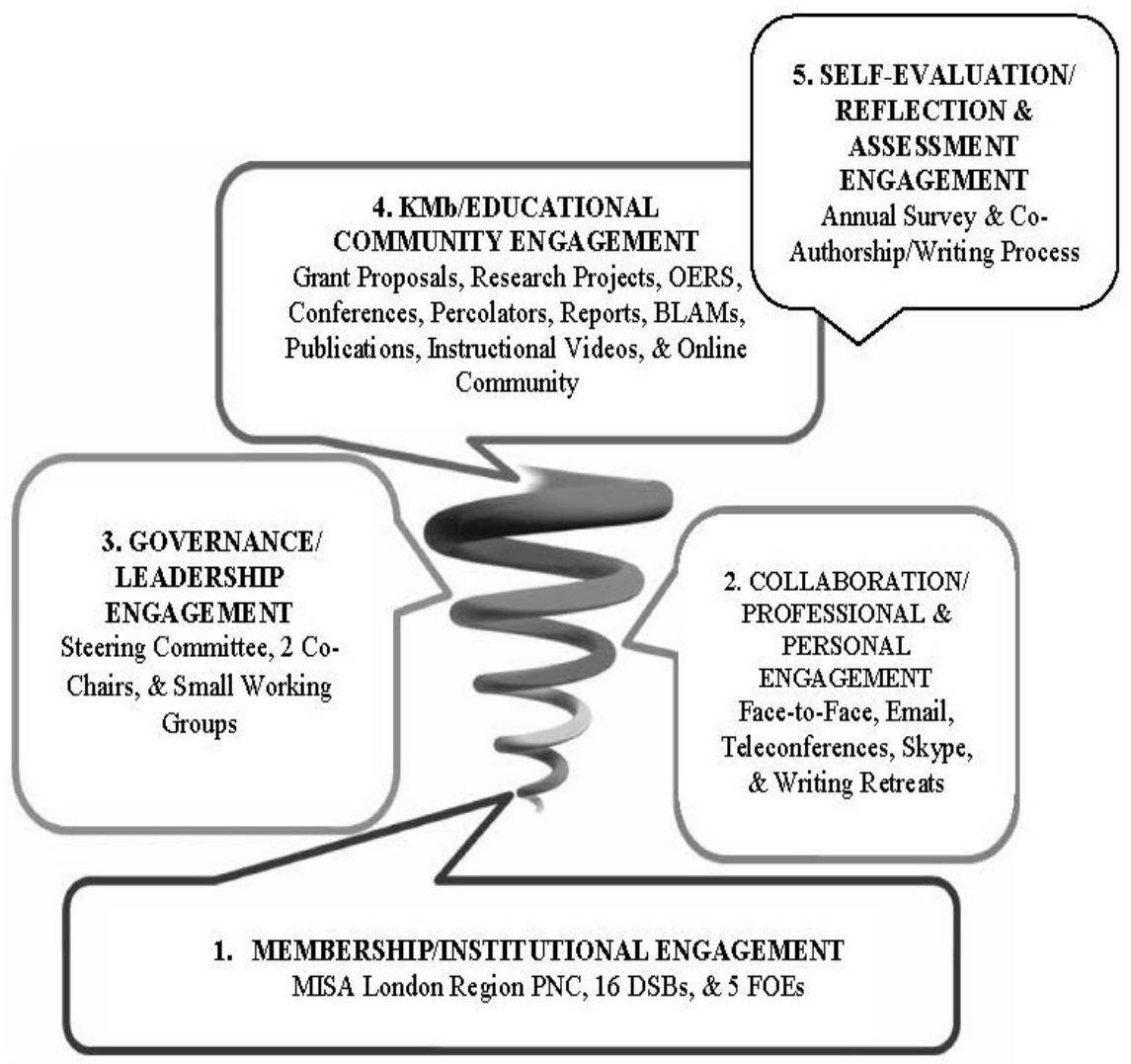

Figure 1: SURE scholarship of engagement model.

Encouraged by the successes of our projects, we have continued growing the SURE network to its full potential. Our members reported being identified by our institutions as SURE representatives, having a vested interest in "finding ways to make research and its use valuable and easy for teachers to use" (SURE member, Self-Assessment Survey, 2012), working as a team, knowing people on SURE, being willing to experiment and collaborate, and sharing a common mission, vision, and values, as main pillars of our collaboration.

Although we had developed a mission and a vision from the very beginning of our evolution, some committee members thought that we needed value statements, such as "what matters at the end of the day are kids in schools" (University representative, personal communication, 2009). It was also suggested that we must collectively recognise that SURE is not a vehicle for furthering faculty members' careers, but a means of improving educational practice. Responding to this suggestion, some university representatives noted that serving on the SURE committee did not advance their careers. At the same time, some committee members did not feel that SURE's dual identity was problematic; they felt fully integrated and contributing members of the SURE community. 
Another complexity identified by the steering committee was that even the voices of school board researchers at the table often differed. How much say did they have? Some board researchers felt that their "influence within the SURE Committee is sometimes extremely limited" (DSB representative, personal communication), especially in terms of generating ideas and contributing to SURE initiatives (e.g., writing grant applications, research reports, and journal papers). Integral for sustaining SURE was the development of trust and mutual respect, while actively collaborating on joint projects served to strengthen the bond and working relationships. We have sustained SURE through a flexible and fair approach to meetings and writing sessions, although workload- and contribution-related discrepancies and tensions persisted. SURE committee chairs and projects/small working groups' leaders have encouraged members to contribute in any way possible through Skype, Google docs, or conference calls (as noted in the minutes). As a committee, we have also been careful to schedule meetings in centrally located venues to minimize travel time and expenses. Hosting our meetings in our own institutions - including universities and district school boardshas also eliminated rental costs. Over time, we initiated the practice of joint co-chairs, with one representing each sector-universities and school board membership. The coincidence that our first co-chairs were from one geographic location may have facilitated face-to-face planning meetings. We also invited graduate students to many events such as research festivals and 'percolator' events, thus contributing to scholarship of engagement in and for education.

While our common ground was dedication to scholarship of engagement and bridging the research-to-practice gap, we grew to understand that school boards and universities as institutions valued some outcomes differently. For instance, after several committee members obtained an external grant, with the application supported by letters from all five universities, several school boards, and the SURE committee, tensions arose. Some SURE members wondered who is driving a committee's agenda and challenged us to reconsider our mission and vision. We started asking the following questions: Are we knowledge brokers or researchers? Should we facilitate school board-university collaborative projects or conduct research ourselves? Which contribution would be most valuable for the field? We noted:

The need to define our relationships is a pressing issue because it has become complex and there is confusion over what/who is funded from which grant, who owns intellectual property, who controls an externally funded project, and the role of the whole group vs. working group. (Meeting minutes, April 20, 2012)

It became apparent that having tangible outcomes was a key for engaging the education community, influencing the field, and sustaining our network. Our first tangible outcomes were a research report to the Ministry of Education and an academic paper. We were advised by our DSB colleagues that the research findings needed to be packaged in a more accessible form if they were to be used by practitioners. We subsequently began creating infographics, videos, and organizing $\mathrm{KMb}$ events, which enriched our scholarship of engagement, as detailed in the feedback participants provided following SURE events. 


\section{Participants' Feedback following SURE Event}

In 2013-15, we organized five $\mathrm{KMb}$ events in the London region. Over 300 people attended these events (including teachers, university researchers, graduate students, ministry representatives, school boards personnel, etc.). Overall, the feedback was positive. Most of participants' post-event evaluation survey comments addressed enhanced opportunities for collaboration, connections, and networking. Representative sample comments included:

It was a great event and I am happy that I attended. I find sessions like these very beneficial towards building capacity and breaking down silos to help us learn more of what others are doing, to learn from each other, and to share our experiences towards greater capacity building.

I learned a lot about collaborative research initiatives within my region.

(Participant Surveys, Research to Practice Symposium: Building Partnerships in Education, Nipissing University, Brantford, March 1, 2013)

Allowing for good dialogue regarding research in various contexts. (Participant Survey, Research to Practice Symposium: Ignite Festival, Western University, November 23, 2013)

Something useful I learned today that I will apply in my daily work [is the] value of collaboration in math and focusing on persistence and stamina as a valued goal.

I went into the conference with my own lens as a current classroom teacher and then realized I needed to change that perspective to a leadership one as there were many board leaders in the room such as principals and coordinators. Having said this, I did not gain as much to improve my teaching practice with regards to new lesson planning ideas as I did for understanding a system perspective for how math can look system wide and how initiatives are planned based on data. Once I viewed the conference from a leadership lens I enjoyed it more and took in learning from that perspective. It was definitely worthwhile to be able to attend such a conference and I am grateful for the opportunity!

(Participant Surveys, A Math and Technology Research Percolator: Looking at Collaborative Inquiry, Western University, April 30, 2015).

When asked to identify areas for improvement, "spreading the word" amongst more educators, and the inclusion of opportunities for sharing resources and hands-on activities, were often reported by participants:

I was disappointed that there were not more participants. You and your committee planned well for this day and I am not sure why people are not coming out to join. Maybe this is something that you can deconstruct and explore other avenues to reach out to people and get them involved and participating. This is an important initiative but the word is not spreading. (Participant Survey, Research to Practice Symposium: 
Ignite Festival, Western University, November 23, 2013)

Provide more and better opportunities for sharing resources and include more hands-on activities in the presentations. (Participant Survey, A Math and Technology Research Percolator: Looking at Collaborative Inquiry, Western University, April 30, 2015)

\section{Governance Model}

Our collective response to some of the dilemmas outlined in this paper was to develop a governance model featuring co-chairs from a university and a school board (see http://www. surenetwork.ca/about-us/). This model has helped us negotiate rights and responsibilities, as well as sustain our partnership over time. It added a structure that has shaped our group purpose and direction. It grounded us. As detailed in the minutes of our October 18, 2013 meeting, when we first talked about implementing a governance model, there was fear that something would be lost. Both university and school board members feared that a governance model would bring Robert's Rules to our setting and decrease the informal, unstructured, and warm discussions we were having and possibly stifle new, unanticipated areas of conversation. We were careful in articulating the governance model in a way that helped us with structure, leadership, and direction but did not take away from the camaraderie we had developed. We purposefully rejected Robert's Rules for consensus-building and used our agendas as a means of making sure that we allotted time for all of our items and initiatives. Importantly, we also managed to provide time for conversational tangents that deviated from the agenda items. A school board representative noted: "Going off on tangents is when things get interesting and innovative!” (Personal communication, June 1, 2015).

\section{New Pathways to Education Research, Policy, and Practice}

Understanding that key leadership at the top of the organization is critical to champion any program or initiative, we note that our work might have been more influential if SURE had included active members who were senior administrators (i.e., University Deans and School Board Directors of Education and Superintendents). Despite this challenge, we have developed a greater awareness and knowledge of each other's strengths and interests. SURE has enabled us to understand the processes and priorities of each member's institution more clearly. We have made an impact within member boards, faculties of education, and across the province with our scholarship of engagement. One of our members stated in the SURE Self-Assessment Survey: "Bringing together so many different organizations in a unique partnership—wow! What potential."

One of our key initial accomplishments was the completion of the Teacher-Researcher study and the dissemination of these results (Martinovic, Wiebe, Ratkovic, Willard-Holt, Spencer, \& Cantalini-Williams, 2012). This first research project that we completed together helped us to look at how to bring research into classrooms and felt ground-breaking in terms of collaborating with each other. This study laid the foundation for many of our subsequent

Engaged Scholar Journal: Community-Engaged Research, Teaching, and Learning 
endeavours, such as the 2013-2014 SSHRC-funded project which allowed us to complete numerous $\mathrm{KMb}$ activities. Overall, SURE accomplished an extensive $\mathrm{KMb}$ Plan, which is in the further text organized by Cooper's (2011) strategy. According to our Summary Report from 2011-2013, we developed a website, participated in OERS (Martinovic, Spencer, Ratkovic, Cantalini-Williams, \& Landon, 2012), created research reports and research briefs, published a paper in the research journal (Martinovic, Wiebe, Ratkovic, Willard-Holt, Spencer, \& CantaliniWilliams, 2012), organized and facilitated numerous networking and KMb events (Martinovic, Donohoo, Ratkovic, Willard-Holt, Grierson, Spencer, \& Wiebe, 2013), presented at national and international conferences, and developed a video series for teachers-researchers.

Our 'scholarship of engagement' products are available on the SURE (http://www. surenetwork.ca/) website. These SURE activities helped create a growing network of educators who are willing to use, design, and conduct research, and communicate their findings orally and/ or in writing. These outcomes are significant for building a holistic and integrated education community and increasing teacher efficacy. Despite our successes, it remained challenging to incite a deep change in relationships between our institutions, as our institutional leaders were less involved than faculty members and research personnel. However, developing this joint research community was a critical undertaking, given that effective teaching practices are based on or substantiated by research (Ramsey, 2000). Arguably, given the participation of educators and teachers in our many events, SURE has facilitated research-to-practice agendas at the school and/or classroom level for over seven years.

In congruence with Gore's (1995) literature review, SURE findings suggest that democracy, trust, open communication, time commitment, rewards and recognition, common goals, joint responsibility, and a focus on change are important when promoting scholarship of engagement and building genuine partnerships in education. Lessons learned about SURE will inform school board-university collaborations that operate on both large and small scales, bringing together the "two worlds" (Bartunek \& Rynes, 2014). For us, SURE has been a transformational partnership at the regional level similar to the partnership described by Butcher, Bezzina, and Moran (2011). Our conviction that neither scholars nor practitioners know education better, but that we know it differently (Ancess, Barnett, \& Allen, 2007), provided a fertile ground for our community-engaged collaborative work (Khanenko-Friesen, 2015). Our partnership laid the groundwork for future collaborative projects and has provided insight and direction not only provincially, but also at national and international levels. While some scholars claim an increasing gap between academics and practitioners (Tsui, 2013), we have demonstrated possibilities for bridging the gap between these two worlds. Uncovering tensions associated with academic-practitioner collaboration informed our work and generated "new types of scholarly inquiries” (Bartunek \& Rynes, 2014, p. 2) and engagements across educational settings.

\section{The Road Ahead}

Analyzing our experiences and writing this paper provoked us to re-assess our community engagement model and reflect on our journey. While we were getting lost in the woods of our beginnings, our governance and self-assessment compass took us back to the core of our 
existence, to our mutually beneficial relationships. We became even more cognizant of the values that we share and of the partnership activities that are recognized in the field. At the same time, we embraced the complexities and contradictions of our experiences. We used this research and writing process to reflect on our seven-year long journey, not leaving many stones unturned along the way. We encountered some surprises, which led to new questions and deeper understanding of our relationships and future goals. Moreover, we opened ourselves to the possibility of change and continued on this road to build understandings between and among academic and professional communities in education.

In hindsight, the SURE network has evolved into a flexible collegial partnership that is characterized by collaborative research, evaluation, and scholarship; collaborative research ethics review; recognition and appreciation of each other's priorities, skills, and contributions; and discovery, integration, knowledge-sharing, and knowledge-application. Our key accomplishments include collaborating across school boards and universities; facilitating research-to-practice activities within member boards, faculties of education, and across the province; developing relationships and building trust; creating $\mathrm{KMb}$ events and products; and sustaining our collaboration since 2008. At the same time, numerous tensions and challenges arose along the way, including differences in timelines between school year and grant deadlines; different pressures and priorities; issues regarding data ownership and authorship; powerimbalance due to different sources of funding (Ministry vs. SSHRC); struggles with building and enacting a governance model with accountability; and lack of recognition and incentives for the boards' personnel related to their work as researchers or their contributions to research. We conclude that it is important to continue our discussions and collaborations, even when tensions or challenges arise, so that we evolve collectively both as a group and as individuals. We concur with Bailey and Koney (2000) that "the implementation of inter-organizational efforts has...much to do with individual relationships" (p. 29), and embrace our journey in the midst of tensions, complexities, and victories.

The SURE model (see Figure 1) discussed in this paper represents the evolution of our scholarship of engagement from establishing a committee, building a collaborative community, developing a governance structure, mobilizing knowledge, and evaluating our practices. The spiral nature of the model reveals the complexity and fluidity of our engagement as well as the need to keep observing, planning, acting upon, and revising community engagement models and practices.

While MISA PNC financial support for SURE meetings and activities ended in 2016, our professional and personal relationships have endured. This essay demonstrates our unceasing commitment to the SURE network, scholarship of engagement, and the field of education.

\section{Acknowledgements}

We are grateful to all the educators and SURE Committee members who participated in our SURE events' evaluations and our survey. 


\begin{abstract}
About the Authors
Maria Cantalini-Williams has worked as a teacher, program consultant, professor and university administrator. Maria has been the principal investigator for studies funded by Ontario Ministry of Education, Higher Education Quality Office, The Learning Partnership, Education Quality Accountability Office and Rideau Hall Foundation. Her areas of research are childhood education, teacher development, work-integrated learning, community engagement and cultivation of innovation.
\end{abstract}

Prior to becoming a university professor, Arlene Grierson spent over two decades as a school board educator. Arlene highly values school board-university partnerships and collaboration. Her research explores models and systems of teacher professional learning such as coaching and mentorship, with attention to the effects of collaboration and scaffolding on teachers' evolving beliefs and practices.

Sally Landon was the researcher and MISA Leader for the Grand Erie District School Board until recently. Her work involved system research, data analysis, program evaluation, reviewing research applications and supporting the board improvement planning process. Information privacy became an emerging focus and she moved to Hamilton-Wentworth District School Board to continue that work.

Dragana Martinovic (corresponding author) is a Professor of Mathematics Education at University of Windsor, a Fellow of the Fields Institute for Research in Mathematical Sciences and a Co-Director of the Fields Centre for Mathematics Education. Dragana leads different networks (e.g., SURE) and communities of practice (e.g., Mathematics Leadership CoP), implementing ideas of engaged scholarship through knowledge mobilization and enhanced collaboration between educators, researchers, and policymakers. Email: dragana@uwindsor.ca

Snežana Ratković is a Research Officer and a Research Fellow in the Faculty of Education at Brock University. Since 2005, Snežana has worked extensively with teachers, teacher candidates, teacher educators, and school administrators in the London region. She is a member of the School Board-University Research Exchange (SURE) Network and the BrockGolden Horseshoe Educational Consortium (BGHEC). Snežana's scholarship focuses on forced migration and settlement, teacher identity, transnational and transdisciplinary teacher education, women studies, research ethics, social justice leadership, academic writing and publishing, and knowledge mobilization.

Terry Spencer is the Research and Evaluation Officer with the London District Catholic School Board. In this capacity, he provides data management and statistical analysis, consultative and decision-making support to Board and school staff. He serves as a liaison with staff, community agencies and educational institutions on research and evaluation projects. 


\section{References}

Ancess, J., Barnett, E., \& Allen, D. (2007). Using Research to inform the practice of teachers, schools, and school reform organizations. Theory Into Practice, 46(4), 325-333.

Bailey, D., \& Koney, K. (2000). Strategic alliances among health and human services organizations. From affiliations to consolidation. Thousand Oaks, CA; Sage.

Bartunek, J.M., \& Rynes, S.L. (2014). Academics and practitioners are alike and unlike: the paradoxes of academic-practitioner relationships, Journal of Management, 40, 1181-1201.

Boyer, E. (1996). The scholarship of engagement. Journal of Public Service and Outreach, 1(1), 11-20.

Butcher, J., Bezzina, M., \& Moran, W. (2011). Transformational partnerships: A new agenda for higher education. Innovative Higher Education, 26, 29-40.

Campbell, C., \& Fulford, D. (2009). From knowledge generation to knowledge integration: Analysis of how a government uses research. Paper presented at the Annual meeting of the American Education Research Association (AERA), San Diego, CA.

Coburn, C.E., \& Penuel, W.R. (2016). Research-Practice partnerships in education. Educational Researcher, 45(1), 48-54.

Cooper, A. (2011). Knowledge mobilization intermediaries in education across Canada. Unpublished doctoral thesis, University of Toronto, Toronto, Ontario, Canada.

Flyvbjerg, B. (2006). Five misunderstandings about case-study research. Qualitative Inquiry, 12, $219-245$.

Foucault, M. (1980). Truth and power. In C. Gordon (Ed.), Power/knowledge: Selected interviews and other writings by Michel Foucault (pp. 109-133). New York, NY: Pantheon Books.

Gajda, R. (2004). Utilizing collaboration theory to evaluate strategic alliances. American Journal of Evaluation, 25, 65-77.

Gajda, R., \& Koliba, C. (2007). Evaluating the imperative of intra-organizational collaboration: A School improvement perspective. American Journal of Evaluation, 28(1), 26-44.

Garman, A.N. (2011). Shooting for the moon: How academicians could make management research even less irrelevant. Journal of Business and Psychology, 26, 129-133.

Gore, J. (1995). Emerging issues in teacher education. Innovative Links between Universities and Schools for Teacher Professional Development. A National Professional Development Project. Murdoch University.

Hsieh, H-F., \& Shannon, S.E. (2005). Three approaches to qualitative content analysis. Qualitative Health Research, 15(9), 1277-1288.

Hunkins, F., Wiseman, D., \& Willams, R. (1995). Supporting Collaborative Inquiry. In R.T. Osguthorpe (Ed.). Partner schools: Centers for educational renewal (1st ed.). San Francisco: Jossey-Bass Publishers.

Khanenko-Friesen, N. (2015). Building engaged scholarship in Canada: Introducing the first issue of the Engaged Scholar Journal. Engaged Scholar Journal, 1(1), 3-11.

Kondracki, N.L., \& Wellman, N.S. (2002). Content analysis: Review of methods and their applications in nutrition education. Journal of Nutrition Education and Behavior, 34, 224-230.

Lang, L. (2001). Searching for collaborative balance: Negotiating roles in school-university partnership research. In M. Richards, A. Elliott, V. Woloshyn, \& C. Mitchell, School - University Collaborative Research (Eds.). Collaboration uncovered: The forgotten, the assumed, and the unexamined in collaborative education. Westport, CT: Bergin \& Garvey. pp. 119-142.

Engaged Scholar Journal: Community-Engaged Research, Teaching, and Learning 
Lefever-Davis, S., Johnson, C., \& Pearman, C. (2007). Two sides of a partnership: Egalitarianism in school-university partnerships. The Journal of Educational Research, 100 (4), 204-210.

Martinovic, D., Donohoo, J., Ratkovic, S., Willard-Holt, C., Grierson, A., Spencer, T., \& Wiebe, N. (2013). Putting theory into practice: Connecting students' engagement and equity with teacher access to and utilization of applied education research. KNAER symposium at Canadian Society for the Studies in Education, CSSE 2013, June 1-5, Victoria, BC.

Martinovic, D., Ratkovic, S., Wiebe, N., Willard-Holt, C., Spencer, T., \& Cantalini-Williams, M. (2012). Reporting research is not enough: Mobilizing research collaboration across school districts and faculties of education. AERA 2012, April 13-17, 2012, Vancouver, BC.

Martinovic, D., Spencer, T., Ratkovic, S., Cantalini-Williams, M., \& Landon, S. (2012). Evaluation of the SURE (School Board University Exchange) Partnership and its Impact on Building Research Capacity in Schools. 7th Annual Ontario Education Research Symposium, OERS 2012, Toronto, ON.

Martinovic, D., Wiebe, N., Ratkovic, S., Willard-Holt, C., Spencer, T., \& Cantalini-Williams, M. (2012). 'Doing research was inspiring': Building a research community with teachers. Educational Action Research, 20(3), 385-406.

Ontario Ministry of Education. (Accessed July 15, 2016). MISA Professional Networks. Retrieved from http://www.edu.gov.on.ca/eng/research/PNC.html

Peattie, L. (2001). Theorizing Planning: Some Comments on Flyvbjerg's Rationality and Power, International Planning Studies, 6(3), 257-262.

Ramsey, G. (2000). Quality methods: revitalising teaching: critical times, critical choices: Review of teacher education in NSW. Sydney: Department of Education and Training.

Ross, J., Rolheiser, C., \& Hogaboam-Gray, A. (January 1999). Effects of collaborative action research on the knowledge of five Canadian teacher-researchers. The Elementary School Journal, 99(3), 255-275.

Shapiro, D.L., Kirkman, B.L., \& Courtney, H.G. (2007). Perceived causes and solutions of the translation problem in management research. Academy of Management Journal, 50, 249-266.

Short, K. (2009). University - School District Research Exchange: The London Region Story...So Far. Unpublished report for MISA.

Tsui, A.S. (2013). The spirit of science and socially responsible scholarship. Management and Organization Review, 9, 375-394.

Tuckman, B., \& Jensen, M. (1977). Stages of small group development revisited. Group and Organizational Studies, 2, 419-427.

Vermeulen, F. (2005). On rigor and relevance: Fostering dialectic progress in management research. Academy of Management Journal, 48, 978-982.

Woodland, R., \& Hutton, M. (2012). Evaluating organizational collaborations: Suggested entry points and strategies. American Journal of Evaluation, 33(3), 366-383.

Yardley, B., \& Lock, G. (2004). University-School partnerships: Schools' perspectives during the early stages of development. Australian Journal of Teacher Education, 29(2), 1-10. 
APPENDIX: TCAR-based findings after SURE self-assessment survey, February 2012.

\begin{tabular}{l} 
Areas of Strength \\
\hline Dialogue \\
- Logistics (pre-planned agenda and good \\
minutes) \\
- Respect (professional tensions are \\
negotiated through respectful language \\
and support; discussions are open; desire \\
to learn about each other's worlds; active \\
participation by all is encouraged) \\
Decision-Making \\
- Inclusive practice (being open to different \\
points of view in the process of making \\
decisions; most decisions are reached out \\
by consensus) \\
- Commitment to decisions (enacting the \\
decisions agreed upon)
\end{tabular}

\section{Action}

- Coordination (team actions are well coordinated)

- Work ethics (committee members are inspired by their SURE colleagues)

- Collaborative strategies (members work together well and they are good at following through on what they agree to do)

\section{Evaluation}

- Commitment to evaluating the collaboration process (findings are shared among us, mostly informally, and with a larger education community through formal means)

- Team expertise (in evaluation, data analysis, and evidence-based decisionmaking)

- Commitment to improving educational research and practice

\section{Decision-Making}

- Lack of protocol/policy for decisionmaking

- Limited opportunities for self-assessment of decision-making processes

- Complexities and challenges of inclusive practices (issues with follow-up and collaborative supervision)

\section{Action}

- Unbalanced involvement and/or contribution

\section{Evaluation}

- Lack of quantitative data about team practices/outcomes (we evaluate the work of others more often than our own work) - Lack of regular and systematic approach to evaluation 